\title{
The Influence of the Modern Sports Teaching Environment on Teaching Quality
}

\author{
Xueda Yang \\ School of sports, Yan'an University, Yan'an 716000, China \\ yangxueda1976@163.com
}

\begin{abstract}
With the development of education reform, the teaching quality has once again become a hot topic in modern teaching. However, to enhance the quality of teaching they need good teaching environment as a support, not good teaching environment, to enhance the quality of teaching will be limited. In this study, by the methods of literature study, logical analysis, the effect of physical education teaching quality of hard and soft environment was discussed, in order to provide useful reference for improving the quality of teaching and improve the teaching environment.

Index Terms - sports, teaching environment, teaching quality, influence
\end{abstract}

As everyone knows, the sports teaching is one of the important teaching activities in school education, the teaching quality of physical education is directly related to the foundation of cultivating talents. No sports teaching environment, organization and arrangement of teaching process is difficult to implement. The PE teaching environment is the basic condition of physical education teaching activities, is the combination of all the condition to carry out teaching activities need. Obviously, the PE teaching environment with respect to a relatively microscopic teaching environment and teaching environment, so it can not be free from the teaching environment and isolated existence. Excellent teaching and learning environment is the premise to carry out effective teaching activities, is the basic guarantee for smooth teaching activities. In the course of sports teaching, good teaching environment has a positive guidance, cultivate, inspire and health effects, is of great significance to the harmonious development of children. The study of the relationship between China's sports teaching environment and teaching quality is not very comprehensive, very system. And the impact of this article mainly from the sports teaching environment hard, soft two environment on the quality of teaching as a starting point for research and analysis, to explain its relationship between, in order to improve the teaching quality of sports provides a useful exploration.

\section{Effect of sports teaching environment of teaching quality}

"To create one environment", the environment is the objective world in which people live and be influenced by it, the visible impact on the environment is very important. Teaching environment is one part of the environment, is the sum of effects throughout the teaching process of teaching and learning of physical factors and human factors. In its broad sense refers to all the social environment influence teaching such as social system, science and technology, family and community conditions belong to the teaching environment; the narrow sense refers to the needs of school teaching material, institutional and psychological environment such as a campus, teaching facilities, school, classroom atmosphere and teacherstudent relationship. The $\mathrm{PE}$ teaching environment is an important factor in teaching activities, also is the important content of teaching theory in modern sports. This research embarks from the narrow sense of the concept, the sports teaching environment is divided into hard, soft environment. The material factors hard environment of physical education sports teaching environment, including the venues, equipment, multimedia and other hardware sports teaching measures, as teaching materials and teaching guarantee, directly affects the quality of teaching.

\section{A. Physical facilities environment}

Environmental facilities are effectively implemented and material guarantee of PE teaching. Mainly including sports venues, facilities, Sports equipment and other factors, therefore, the teaching facilities are available will be related to the teaching quality of physical education. In the school sports teaching, sports venues, primarily for the service, sports teaching but, with the development of the society, its function is becoming more diverse, a variety of functions has a set of teaching, athletic performance, entertainment, fitness in one. Therefore, the construction of a good physical education facilities will provide a full range of services for our teaching and other aspects. Of course, not a short-term project construction material facilities, it is affected by the financial and material resources, manpower and time and other factors, will need to go through a process of development. In this process, the construction speed, perfect degree depends mainly on the school's economic status and school leadership on its understanding degree -- understanding degree function and quality of its meaning.

To enhance the quality of teaching subject to the hard environment of PE teaching effect and construction. If the teaching space, lack of equipment, its teaching quality must be greatly reduced, dozens of people on a basketball court and a badminton court class, the teaching organization, the density and intensity of exercise will bring bad influence. The crowded, noisy class environment will have a bad effect on students' initiative, enthusiasm and interest, and further influence the quality of teaching. Visible, effects of physical teaching material facilities for sports teaching in many aspects and deep, particularly in the current school enrollment expansion and ensure the quality of teaching and at the same 
time, must strengthen environmental material facilities construction. Usually, different regions, different schools, there exist certain differences in environmental conditions, number, has the environmental conditions of quality, type is also different. All schools in the environment and has its own advantages and characteristics. Schools can also be based on actual funding and geographical environment, obtain raw material locally, suit one's measures to local conditions, make full use of the local environmental conditions, scientific design, ingenious arrangement of various equipment and facilities, especially in remote mountainous and rural area school, the school open space around their houses, trees, hills, waste materials, multifunctional development of refining the ideal venues and facilities, it is also an efficient way out the construction of sports facilities environment.

\section{B. A application of modern information technology}

The teaching process is the flow of information in a multiple channel engineering. "The teacher, preaching impart knowledge and solve doubts also." "Transfer" and "industry" is a kind of information exchange between teachers and students. In this technical high speed development of society, computer is no longer a luxury and mysterious things, so, the multimedia teaching has crept into the classroom. Diversity of multimedia applications of modern information technology can effectively mobilize students to participate in a variety of senses information acceptance activities, improve the information acceptance of quality, but also can effectively increase the information flow in unit time, improve the efficiency of information transmission. Teachers in the teaching with use of television, slides, video equipment and multimedia technology, image, text, etc. a variety of sensory stimulation factors to students, so as to obtain the best effect of information transmission. On the other hand, various audiovisual facilities are deficient, restricted the teaching information exchange and teaching methods will greatly.

In the physical education activities timely with music, can reduce the student movement technology monotonous feeling, make the brain in the excited state, stimulate the potential, improve the rhythm of movement, eliminate fatigue, relieve tension, to enable students to master the technology in happiness, improve skills. Such as: are we doing calisthenics, students will feel very boring, but if the music, you can achieve very good results. Also, in the end part of class, if equipped with soft and gentle music students can eliminate fatigue, physical and mental relaxation. Multimedia technology into the classroom, the classroom atmosphere relaxed and happy, easy to arouse the students' creative thinking, also can make the abstract concepts concrete, knowledge interesting boring. Therefore, full attention to science and technology teaching means in teaching, the development and improvement of multimedia teaching facilities, conducive to the sports teaching environment and improve the quality of teaching.

\section{Effect of soft environment in teaching environment of teaching quality}

Human factors of soft environment for sports teaching environment, which includes the schools of traditional culture, the classroom atmosphere, teacher-student relationship, and establish the course content choice and so on, all these can have a great effect on improving the students' emotion. Psychology thinks the creation of emotional environment, can make the students know the knowledge in a relaxed and pleasant environment, knowledge. Various factors in the teaching and learning environment to create a democratic, cooperation, inquiry, health classroom atmosphere for students, so that students from the emotion in a positive, free, loose, safety psychology, so as to enable students to enter a free ride to the psychological space. To enable students to actively, active, happy learning, so as to realize the "want me to change to learn" to "I want to learn".

\section{A. Effects of class atmosphere in teaching quality}

Sports the atmosphere of the classroom teaching is a kind of emotion, the emotional state of class collective formed in the sports teaching process. Active classroom atmosphere is good for physical education teachers and students of the trust and emotional exchanges, to help the students to set up the courage to overcome difficulties and confidence, can inspire and mobilize students' enthusiasm in learning. The PE classroom atmosphere we have the experience, can be roughly divided into two kinds: one is a teacher too irresponsible, a lesson to throw a ball or dissolution did not organize, lead to only a few sports lovers can get exercise, while other schools can only stand by watching others battle, or simply back to class learning about other cultures course content, so physical education became the privilege of a few people, contrary to the original intention of the syllabus, PE meaningless; another is because teachers are "responsible". The whole class process in the teachers teach, students learn. The teacher out of a sense of responsibility, afraid of the students failed to learn the knowledge, and take "full hall fill" teaching mode, simply do not understand the students could learn, willing to learn, can accept. The classroom atmosphere is too depressing, students' passion is not released. Even the suppression of student interest in the teaching contents, action is not in place to criticize and even trained, seriously dampened the confidence of the students.

The new PE curriculum standards framework of PE teaching syllabus changed the past divided by the sports curriculum content and arrangement of teaching hours, to construct the content system of physical education curriculum, to broaden the curriculum learning scope. The new sports curriculum standard for physical education teachers will bring a beacon, it gives the selection range of $\mathrm{PE}$ teachers great in content selection class, students, teachers, schools, various regions have considerable space and room for choice, all according to their actual choice process of physical education teaching content. In the respect, has a special role to meet the school teachers and students, the difference of uniqueness, the 
improvement of teaching quality of physical education curriculum in primary and secondary schools is more important. Happiness is only a means, health is the ultimate goal. Through the teachers of the course contents and the teaching method choice to make classroom atmosphere active, let the students finish the exercise purpose in pleasant classroom atmosphere, improving steadily achieve the teaching quality.

\section{B. Effect of interpersonal relationship on the teaching quality.}

In sports teaching, teachers are not only restricted by its internal factors, but also influenced by external factors associated with it. The interpersonal relationship is one of the important factors, to deal with all kinds of interpersonal relationship, and solve various disadvantageous factors affecting teaching, obtained the leadership, work and study in a colleague's care and the support, help to improve their own quality, is beneficial to the teaching work smoothly. Interpersonal relationship is the psychological relations between people and people in the form of social interaction. Harmonious interpersonal relationship between students and teachers help students learning interest and enthusiasm to improve, can let the students accept the knowledge from the teachers, but also willing to approach teachers influence character by environment, the closer the distance between teachers and students. A good relationship between teachers and students is helpful to improve the students' learning motivation, otherwise it will suppress the students' interest in learning, and even tired of teacher's class, and this requires that physical education teachers should focus on establishing a good image in the classroom teaching. Teachers love students, students in turn on the teachers with the corresponding emotional return, will more deeply beloved teacher. "Close its teacher, and the students", when the teacher's love to a certain extent, will produce the phenomenon, from love, love and discipline teacher and his teaching, interest in learning, the successful completion of the quality of teaching and so harmonious teacher-student relationship is helpful to the teaching tasks to improve the. Conversely, decrease the quality of teaching.

Interpersonal relationship as an important factor of psychological environment in physical teaching, the key is in the psychological environment research in the teaching of physical education, interpersonal relationship in physical education teaching mainly include the relationship between teachers and students and the relationship between students and students, because their relationship is an interactive process, so he influence of PE classroom teaching atmosphere, teaching feedback and students' classroom participation attitude and enthusiasm, thereby affecting the quality of physical teaching. In the process of education and teaching, "teacher's dominant, and forms of teaching students" more attention. Therefore, the relationship between teachers and students is no longer limited to the general form of teaching, has gradually extended to the daily care and emotional communication, influence and informal communication between teachers and students to students and management, as well as the role in teaching between teachers and students, some are formal communication incomparable. Because, informal communication between teachers and students is built in between the teachers and the students shared interests, common ideological beliefs such as the basis, the relationship between teachers and students is conducive to eliminate a certain distance, is the communication between teachers and students more freedom, shorten the distance between teachers and students and in the psychological resonance, which is conducive to the smooth teaching activities for.

\section{Effects of selection on the quality of teaching of the teaching content}

Teaching content can affect students' learning motivation, learning motivation is a kind of subjective factors motivating students to learn appears to desire, interest, need and other forms, is an important variable affecting the atmosphere, process, the quality of teaching and learning results of the. If the teacher taught the students are not interested in, the red signal is teaching. The physical education is nothing more than some run, jump, throw those boring track and field events, or a ball is a class a whistle, not only affect the appearance of the class, so most students exercise not in physical education, lost interest in physical education course. With the development of the times, course content should also be constantly enriched, know about the survey data, can stimulate students interest in the project in order to be accepted by students, such as games, basketball, gymnastics, martial arts, shuttlecock, it also shows the students like projects are often those strong interest, have a certain antagonism of, and with the nature of performance projects. Teaching, students should mobilize the initiative under the guidance of teachers, the teachers do the teaching design, teaching driven by the students. According to the change of teaching environment timely and appropriately adjust and optimize the teaching content, help the students to improve the ability of sports.

Confucius said: "know its rather know, know as the music man." When a person engaged in or like a sport item, it will actively mobilize their own state, put our heart into study, otherwise, will be negative, neglect of the heart to cope with their own do not love or is forced to learn knowledge. Therefore, it is necessary to change the traditional education idea, reduce to teach sports technology as the main body of the teaching material system, adding some strong entertainment and can achieve the purpose of fitness project. Such as: 200 meters many games, entertainment is strong, have a certain strength, to achieve the goal of health care in the happiness. The traditional teaching emphasizes teacher-led, ignoring students' main body status, regard students as passive recipients, movement is only a teacher to increase their burden, it is difficult to mobilize students' learning interest and enthusiasm. To transform from the "want me to learn" to "I want to learn", teachers must according to the requirements of the actual school and curriculum, processed refined on the 
teaching content, to mobilize the enthusiasm of the students, to reach the goal of teaching, improving teaching quality.

\section{Conclusion}

Through the analysis of the teaching of physical education in two kinds of hard and soft environment, relationship makes us realize the teaching environment and teaching quality of the two, understand the importance of teaching quality environment. Scale environment and the teaching of physical education and the number of students has an attachment relationship, particularly in the current under the situation of enrollment expansion, the construction of sports teaching environment is particularly important. Restriction though teaching environment by many objective conditions, but can be by our work, play an initiative role; in a soft environment we have large activity space, make the best possible use of the objective environment, reform and improve the existing conditions, to create a unique sports teaching environment, respect for the personality development of students, PE ability to truly become a flavor, be full of sound and colour of the spirit of paradise, effective guarantee of teaching quality to sports to.

\section{Reference.}

[1] Guo Shuping. The creation of physical education teaching. sports science research teaching situation, optimization, 2001,06.

[2] Wu Zhihui. Several theoretical problems about the teaching environment of. Journal of Northeast Normal University, 1995,05

[3] Liu Yang. The PE teaching environment influence on classroom information interchange. Hubei sports science and technology, 2002,03

[4] Li Ping. English teaching environment influence on classroom information exchange and data., 2005,12

[5] Ding Yi, Liu Xianglin. College physical teaching environment of. Journal of Shenyang University, 1995,08 